\title{
The Impact of Using the Translation Purpose on Translating Medical Terms
}

\author{
Areej Mohammed Al Khamis \\ أريج محمد الخميس \\ MS Translation, IMAMU \\ ماجستير ترجمة، جامعة الإمام محمد بن سعود الإسلامية \\ Administrative Specialist,KSMC \\ اختصاصي إداري مدينة الملك سعود الطبية
}




\title{
The Impact of Using the Translation Purpose on Translating Medical Terms
}

\author{
Areej Mohammed Al Khamis \\ أريج محمد الخميس \\ MS Translation, IMAMU \\ ماجستير ترجمة، جامعة الإمام محمد بن سعود الإسلامية \\ Administrative Specialist,KSMC \\ اختصاصي إداري مدينة الملك سعود الطبية
}

\begin{abstract}
This paper studied the impact of using Hans J.Vermeer's Skopos theory in translating medical terms. Skopos is a theory takes in consideration the source and target texts but focuses on the purpose of translation which usually mentioned in the "Brief".

Skopos theorist believed that professional translaros are able to establish a purpose of translation if they do not have a brief, and the brief of translation will affect their choices in translation strategies. The purpose of this study is to determine how medical translators act if they have a brief or not and if they are able to establish a purpose of translation based on the ST analysis also, if the translators translate oriented to the source text or to the target text.

Data of medical reports were collected from King Saud Medical City and problematic terms were studied on the light of Skopos theory, also, a questionnaire had been designed and distributed among KSMC translators to confirm the results of the reports analysis.

The results from the reports analysis showed that the reduction strategy was most used to translate the collected medical reports, and that the translators were target text oriented in general. I also determined that the translators used reduction strategy when they do not have a brief and tend to be target text oriented. Besides, translators used synonymy and reduction strategies equally when having a brief, although a translator who used the synonymy strategy tended to be source textoriented and ignored the brief. When using the reduction strategy, translators were target textoriented, which indicated that they considered the brief but as an overall, translator tend to ignore the brief when it defined the receivers as non-medical experts. The questionnaire results showed that translators believed that, the brief is essential to the translation process and it often has an impact on their selected TS. If the brief was not explicit, translators are capable to find a purpose of translation by keeping in mind ST and TT and they tend to be TT-oriented. This study will help to improve the
\end{abstract}


production of medical translation as the receivres of TT vary between medical and non-medical experts.

\section{ملخص البحث}

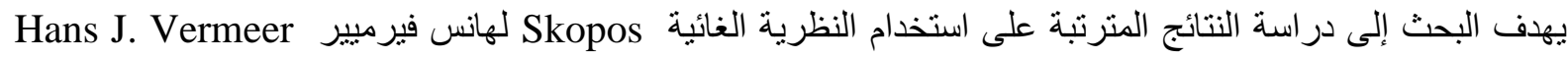
في ترجمة المصطلحات الطبية ، و هي نظرية تأخذ بعين الاعتبار النص الأصل والنص الهدف وتركز على الغاية المتوخاة من

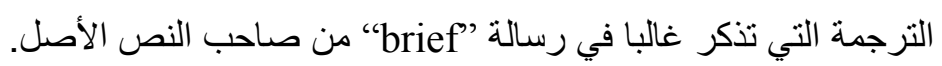
يوضح البحث كيفية تأثير الرسالة في اختيار المترجم لاسترانيجيات الترجمة، وان كان يميل لأخذ النصل الأصل أو النص الهدف

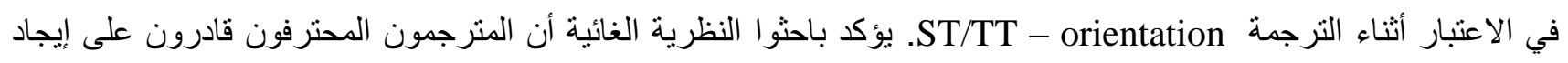
هدف للترجمة ان لم يرفق رسالة توضح ذلك وانها ستؤثر على اختياراتهم لاستر اتيجيات الترجمة. الهدف من الدراسة هو تحديد

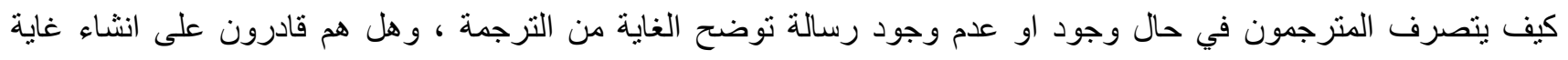
للترجمة اعتمادا على تحليل النص الأصل، وكذلك ان كانو سيضعون في الاعتبار النص الأصل او النص الهدف اثثاء الترجمة. ولهذا تم جمع تقارير طبية من مدينة الملك سعود الطبية ودر اسة المصطلحات الطبية على ضوء النظرية الغائية، وكذلك تم تصميم

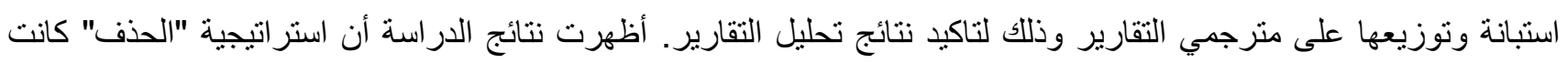
الاكثر استخداما في ترجمة المصطلحات الطبية و بشكل عام كانوا اكثر ميلا لاخذ النص الهدف في الاعتبار وفي حال عدم حصول المترجم الطبي على رسالة توضح متلقي النص الهدف، قام المترجمون باستخدام استراتيجية الحذف وكانوا أكثر ميلا لاستخدام المصطلحات الطبية الدارجة في اللغة الهدف. أما عند حصولهم على رسالة توضح المتلقي للنص الهدف، فإن

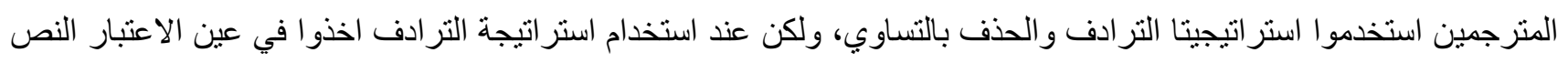
الأصل ، اما في استر اتيجة الحذف كانوا اكثر مبلا لاخذ النص الهدف في الاعتبار. يؤكد المترجمون في نتائج الاستبيان أن الرسالة ’brief’ إيجاد غاية من الترجمة في حال لم يكن هناك رسالة صريحة وذلك بالاخذ بعين الاعتبار النص الأصل والنص الهـف، ويميلون للنص الهدف أثناء الترجمة. هذه الدراسة ستساعد في تطوير مخرجات الترجمة الطبية، حيث ان متلقي النص في الترجمة الطبية يتنو عون مابين متخصصون و غير متخصصون في المجال الطبي. 


\section{INTRODUCTION}

Medical language has a specific purpose as well as its own characteristics and features. It is based mostly on Greek and Latin terms and abbreviations. In order to have a professional medical language, medical translators should be have a medical background so that they would be able to practice with medical terms. Moreover, medical translators should be capable of completing intralingual and interlingual translations since medical language is comprised partly of terms and abbreviations that are designed to save time and effort for the benefit of the patients.

The register and tone of the medical language defines its complexity, thus, has been reflected on the role of the translator to define each register to choose the correct or most appropriate equivalence during the translation process.

\section{Background of the Study}

The "brief" is the main concept in Skopos theory, but the studies related to briefs are not much like the studies examining Skopos theory in general. However, Fraser (1996) has conducted several studies related to the brief. One of these study-considered the base stone of the others, was focused on the immediate retrospection and the "think aloud protocol" (TAP) for 12 community professional translations. In this study, symphasizing the influence of the translation brief and TL receiver on translators' behavior were determined. Participants were asked to translate an article without a brief; they all agreed that it is challenging to fulfil the purpose of the task and translate professional text to laypeople as they need to go beyond the context to create communication bonds.

As a result, it can be concluded that translators pay great attention to translation briefs, as they play a major role in the translation process. However, some professional translators do not request for a brief and this may be because professionals can establish a translation Skopos without having a brief. Nord (1997) believed that professional translators working on certain translations do not need an explicit brief but that they will establish one depending on their experience. Experienced professionals know the specific function of their texts; they also know their clients' requirements and the addressees of the TT.

Schjoldager and Zethsen (2003) also conducted a study on the brief and the establishment of Skopos. Their study involved five professional translators in one focus group. They discussed the purpose establishment; after two months, the scholars conducted individual follow-up interviews with each translator. The results showed that translators establish a Skopos depending on the type of text, headline of translation, client name, and ST analysis. These results agreed with Nord's assertion that professional translators do not require an explicit brief, as they are able to establish one based on their previous experience.

Jääskelainen (1989, 1990) conducted several studies on the relationship between the ST's intention of "purpose" and the TT's purpose. She studied fifth-year translation students and divided her 
participants into two groups. Each group was given a text to translate along with an assignment for the translation, which can be considered to be a brief. One group had an assignment that made the TT function slightly differently than the ST function; then, she observed how members of that group treated the brief. The participants took into consideration the brief while translating, confirming that translators are aware of the importance of the brief and that the TT's intention can be different from that of the ST.

Depending on these studies, it can be said that translators are usually aware of the importance of the brief, its role in the translation process, and how it leads to a successful translation. In some situations, they either ask for a brief or ask to have more information about the TT's receivers to help them establish a Skopos. Still, professional translators are able to establish a Skopos without a brief due to their experience in the field and with ST analyses.

In this study, I examined the impact of the briefs in translating medical terms and if the professional translators are able to establish a purpose of translation if they do not have a brief.

\section{Purpose and questions of the study}

The purpose of this paper is to study how translators connect these two groups to improve translation products to avoid misunderstandings as using everyday English will not be sufficient to complete a medical translation task.

The present study tried to answer the following questions:

1- What strategies do translators commonly use when translating medical terms?

2- In the case of having a brief or not, how do medical translators respond (TT or ST oriented)?

3- What are the differences between translating medical terms with or without a brief?

\section{Skopos Theory}

Critics of translation in its early stages were interested in comparing the ST with the TT, and investigating the differences between the two texts from a mentalist view, which took an equivalence-based approach. Skopos theory is based on the action theory in which every action has a purpose. Vermeer, the founder of Skopostheorie (1970), believed that translation was an action that must have a purpose, which is assigned by the translator's commission. This theory (Skopos) underwent four stages of development. In the 1970s and 1980s, Reiss (1970) applied a functional, or communicative, consideration to the texts, looking for equivalence based on the text as a whole, rather than at the word or sentence level. Similarly, Holz-Manttari (1984) presented translation as an action that involves jargon, an initiator, a commissioner, a ST producer, a TT producer, a TT user, and a TT receivers which represents the theory of action.

Reiss differentiated between four kinds of texts: informative, operative, expressive, and audiomedial. In 1984, Vermeer and Reiss presented a general translation theory that worked with all kinds 
of texts in their book Grundlegung einer allgemeine [Groundwork for a general theory of translation], which focused on the Skopos theory and how to apply it to different texts.

Nord's book Translating as a purposeful activity (1997) considered the Skopos theory and ST analysis to explain how the information provided in the ST could affect the translator's choice of translation strategy. She differentiated between two types of translation: documentary translation and instrumental translation. Documentary translation focuses on the communicative value of ST, allowing the ST initiator to communicate with the TT receiver by considering the cultural aspects of the ST. The culture, structure, and function are defined and dominate the ST-oriented documentary translation, which is commonly used in literal translation works. In instrumental translation, the purpose of the translation requires starting a new function in the communicative value between the ST and TT so that the TT will remain the function of the ST, but will have the culture and norms of the TT. This can be referred to as a TT-oriented approach.

Halliday (1985) linked Nord's theory of ST analysis and register analysis in his work Systemic functional grammar. He believed that the text type influences the register of the language and, thus, divided the register into three variables: the field, or the subject of the text; the tenor, or the author of the text and the intended reader; and the mode, or the form of the text.

House's Translation quality assessment (1997) also focused on the ST and TT registers and on Halliday's idea of field, tenor, and mode. House created a model for translation in which the translator compares the ST and TT to determine whether the sociocultural of the ST or that of the TT should be dominant. Her model described these approaches as overt and covert translation, which are quite similar to Nord's idea of different translation types (documentary and instrumental translation). Overt translation is designed to make the ST more oriented than the TT; it corresponds with Nord's documentary translation. Covert translation aims to make the TT more oriented than the ST, which corresponds with Nord's instrumental translation.

\section{The Term Brief in Skopos Theory}

During the early stages of the development of the Skopos theory, rather than using the word brief, terms, such as "translation commission" or "translation assignment," were used as a translation of the German Ubersetzungsauftrag. Nord (1997)first introduced the term "translation instruction" as a suitable translation for the German term. A 1996 study by Fraser introduced the term brief, which was soon used by all scholars of Skopos theory, including Nord.

An important point to note is that the brief does not equal skopos. In some cases, translators are able to establish a skopos without having a brief. The ideal brief, according to Nord (1997), should have explicit or implicit information about the functions of the text, information about the TT receivers, the time and place where the text will be used, the reasons for producing the TT, and the means of transmitting the text. 


\section{METHODOLOGY}

\section{Design of the Study}

The briefs are usually a message providing information about the due date, fees or TT receivers. The target receivers are the important thing in this study so, some of the medical reports were provided with a litter that the TT receivers were clearly mentioned, but in some, there must be a ST analysis for any line that can help to identify TT receivers as for example in KSMC's medical reports the receivers are usually mentioned at the last line of the MR by informing that this MR was issued on the request of $\mathrm{X}$ department.

In addition, strategies that were used in translating medical terms were presented, and determined if the chosen strategy filled the gap between the different users of the ST and TT. Also, a questionnaire had been designed and distributed among KSMC translators to determine the important of the brief and if it had any influence in their translations.

\section{The Analyzed Reports}

To meet the objective of the study, I analyzed medical reports that contained medical terms that had two different translations or could be translated in multiple ways for laypeople or medical specialists. In this study, I analyzed 10 medical reports from King Saud Medical City (KSMC), which is one of the major medical cities in the Kingdom of Saudi Arabia. I looked for medical reports with ambiguous medical terms to check the consequences of translating these terms in the light of the of the Skopos theory. KSMC reports are typically issued in English and are not translated into Arabic unless an official request is presented. The requests for translation are usually from governments, institutions, or employers seeking information or details about a patient's recovery timelability or condition. The possible ways to obtain an Arabje medical report are as follows:

1. Patient's details in the hospital's system (ENG) Translation $>$ ARA medical report.

2. Patient's details in the hospital's system (ENG) ENG Report issued $>$ Request for Arabic medical report Translation $>$ ARA medical report.

In the first process, the trahslator is the doctor. In the second process, the medical reports are sent to the medical report department for translation.

\section{The Questionnaire}

The questionnaire was selected as a study tool over interviews in order to focus the translators' full attention and time and to prevent the researcher from introducing any impressions or leading influences. It was written in the English language and contained ten semi-open-ended mandatory questions related to the research subject. The questionnaire was pre-tested on two colleagues in the 
same field of work; their notes were considered before administering the questionnaire. Participants were KSMC translators holding bachelor's degrees in English language and translation, having 2 to 4 years' experience at KSMC.

\section{Translation Strategies}

The Skopos theory does not provide translators with any guidelines on how to translate the ST with or without a brief. In fact, Skopos theorists believe that the translation situation is important to consider when selecting an appropriate strategy. Nord (1997) stated that the analysis of the ST will not automatically reveal the function of the TT, although the purpose of the intercultural communication will define the purpose. Therefore, in this study I will investigate the practice of translation by medical translators. I will also determine the strategies that translators tend to use depending on the TT receivers. The focus will be on translating medical terms only. Thus, the strategies that will be discussed deal with translating words or terms that are ST-oriented or TToriented. Our discussion will not include the structure, grammar, or the cultural differences between ST and TT unless it is necessary for the study.

Indirect strategies are more TT-oriented and consist of equivalence, which focuses on the equivalence of the meaning regardless of the ST form. There are three types of equivalence. Cultural equivalence involves translating a cultural ST wordlexpression into an equivalent or nearly equivalent target culture wordlexpression. Functional equivalence involves translating the SL wordlexpression into a TL wordlexpression that has the same meaning or function. Descriptive equivalence involves translating an ST word by describing the concept of the word in the TL. Synonymy uses a TL word that has the same or nearly the same meaning as the SL word. Reduction \expansion adds or omits an element of the ST through the translation process for any reason. Paraphrase is an explanation of the ST words/expressions. Compensation adds what is missed in the ST to improve the accuracy of the TT.

Also, a translation strategies called shifts which include three types. Transposition, which involves translating an ST expression into a TL by changing the grammatical structure or words' classes. Modulation involves changing the viewpoint or the substantial conceptual concept. Componential, to find a TL word that is similar to the SL word but not a synonymy.

Table 1

Translation Strategies Based on Text Orientation

\begin{tabular}{|c|c|c|c|}
\hline \multicolumn{2}{|c|}{ Direct Strategies } & \multicolumn{2}{c|}{ Indirect Strategies } \\
\hline Strategy & Orientation Type & Strategy & Orientation Type \\
\hline Literal Translation & ST & Equivalence & TT \\
\hline TransferencelLoan & ST & - Cultural Equivalence & TT \\
\hline
\end{tabular}




\begin{tabular}{|c|c|c|c|}
\hline Translation\Loan & ST & - Functional Equivalence & TT \\
\hline Through Translation & ST & - Descriptive Equivalence & TT \\
\hline Naturalization & ST & Synonymy (Near) & $\mathrm{TT}$ \\
\hline & & Reduction\Expansion & TT \\
\hline & & Paraphrase & $\mathrm{TT}$ \\
\hline & & Compensation & TT \\
\hline & & Shifts & $\mathrm{TT}$ \\
\hline & & - Transposition & TT \\
\hline & & - Modulation & TT \\
\hline & & - Componential & TT \\
\hline
\end{tabular}

\section{RESULTS AND DISCUSSION}

medical reports that contained medical terms that had two different translations or could be translated in multiple strategies for medical experts and non-medical experts. A table had been designed that contain the source and target terms and the strategy used by the translators and if the medical report had a specific receivers or not also, a suggested translation had been provided. This table help to recognize the behavior of the medical translators regarding the ambiguous terms.

Medical terms usually consist of a root word, a combining form, and a suffix or prefix. For example, the term renogram consists of the following:

Root word: reno (renallkidney)

Combining form: $o$

Suffix: gram (record)

Root words are the main word in a medical term. For example:

gastr-: pertaining to stomach معدي

cardi-: pertaining to the heart قلبي

Combining forms are vowels ( $\mathrm{a}, \mathrm{e}, \mathrm{i}, \mathrm{o}$, or $\mathrm{u}$ ) that are used to make the pronunciation easier, and can be used to combine one or two roots with a suffix or prefix. For example:

One root: neuroplast, where neur- is the root, $o$ is the combining form, and -plasty is the suffix, راب العصب

Two roots: gastroenteritis, where gaster- is the root, $o$ is the combining form, -enter is the second root, $i$ is the combining form, and -tis is the suffix, التهاب المعدة والأمعاء

Suffix is the last morpheme in a medical term and, while it has a meaning, it cannot be written alone, such as:

لاحقة بمعنى ورم لoma: tumor 
-phobia: increased normal fear رهاب، رلع

Adjective suffixes include: - $a c$, as in cardiac قلبي and -ior, as in inferior woun suffixes include -iatry, as in psychiatry (medical treatment) الطب النفسي , and -ist as in optometrist مصحح النظر .

Prefixes occur at the beginning of a term, and can modify or change its meaning. For example, preخضع weans before, as in pre-operation قبل العملية whe post- means after, as in post-nephrectomy Adjective prefixes include bi-, as in bilateral ثنائي and supra-, which means above فوق.

The ambiguity of medical language appears on many levels. On the lexical level, the ambiguity of the terms can differ even in the same tone approach, such as with expert-expert language. For example, a urologist may refer to a "kidney X-ray," just as an orthopedic surgeon would. While the term kidney X-ray contains a special abbreviation of medical use, it is still considered to be a common phrase. However, a urologist may refer to a "renogram" or a "pyelogram" instead of a kidney X-ray to be more specific. Since accuracy is important in a translation, translators must be able to choose the appropriate terms according to the receiver of the TT.

Table 2

Example of Medical Terms Ambiguity

\begin{tabular}{|c|l|l|}
\hline \multicolumn{1}{|c|}{ Common Term } & \multicolumn{2}{|c|}{ Special Terms } \\
\hline Kidney X-ray & Renogram & Pyelogram \\
\hline صورة الحويضة & & \\
\hline
\end{tabular}

The terms used in each category are different. Professionals language is full of medical terms and procedures that are known to medical staff. However, for the other receivers, there must be an explanation of the terms provided since many disease names and medical terms are not commonly used in daily speech.

Nord (1997) stated that professional translators are able to establish a Skopos without a brief depending on the ST analysis, title, and the TT receivers. This study examined the translator choice of TS and compared it with the TT receivers to determine if the translator used a ST- or TT-oriented strategy and used covert or overt translation.

\section{Strategies Used in Translating Medical Terms}

\section{Reduction Strategy}

Reduction strategy is where an element of the ST is omitted through the translation process for any reason. Our analysis showed that the reduction strategy was the most popular strategy used to translate medical report samples; it was used a total of 18 times (34\%), 6 of them were in a medical report that had no briefs. The translator for these reports used a TT-oriented approach in the 
translation; for example, the ST term "ECSWL (extracorporeal shockwave lithotripsy)" was

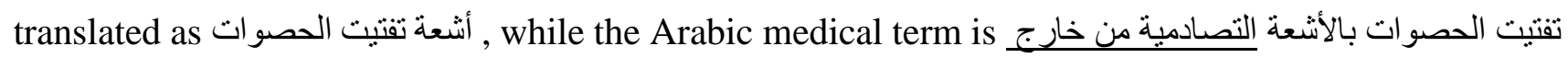
. Since the translation was TT-oriented, the reduction strategy helped the translator save time and communicated well with the TT receivers without adding details that might confused the TT receivers.

However, the term "ECG (electrocardiogram)" was translated as التخطيط الكهربائي , while the Arabic medical term is تخطيط القلب الكهربائي. The missing word is an essential term in the report, even though the TT is understandable. However, providing the full translated term is more professional and useful.

During the analysis, I found two terms for non-medical experts receivers that were not translated at all, which is considered to be part of the reduction strategy. For example, the term “diffuse axonal injury” was ignored, although it could be translated as اصابة مباثرة في المحور العصبي . The term "INR (international normalized ratio)" was also ignored, although it could be translated as . The reduction strategy did not help here since both terms were important. In these cases, the translators were obliged to translate the terms, especially since the receivers were laypeople, which meant that the TT represented one way to understand the patient condition.

In some cases, the reduction strategy was used to help the translator to save time and to help the TT receivers understand the text without being confused with extraneous medical details. I found 12 terms in the medical reports that were translated using the reduction strategy with a brief that indicated the receivers were laypeople. Two of the terms were not translated as previously mentioned, while five terms were translated using a TT-oriented approach to help the receiver avoid complicated medical terms. For example, the term "bicornate uterus" was translated as رحم without mentioning the type of uterus; for laypeople receivers, this translation is acceptable. However, for specialized receivers, it is important to identify the type of uterus involved because it is basic information that could affect the treatment process; for example, in case of pregnancy, a patient could lose her fetus if she did not receive the proper treatment. The term "abducens nerve injury" was translated as اصابة في العصب, and the report mentioned that the patient was seen by optical doctors, which meant that the injury was in the nerves in the eyes. While it was not important to mention the type of nerves injured, for medical specialists it is better to translate as اصابة في العصب المبعد.

However, there were other terms in the reports that were translated using the reduction strategy that directly affected the TT clarity and made the report ambiguous for laypeople. Five terms had a brief that indicated that the receivers were laypeople and were translated using the reduction strategy. For example, the term "spinal clinic" was translated as عيادة الحبل الثوكي, while the reports gave information about the spine and not the cord; in this case, the suggested translation is عيادة العمود 
since both are related to the orthopedic department in hospitals. The term "SAH subarachnoid hemorrhage" translated as نزيف without specifying the place of the hemo- , the term could be translated as نزيف تحت العنكبوتية في الدماغ. These type of details will affect the TT and are important to mention because they help laypeople understand the report. Details can also help specialized medical staff to understand the case.

\section{Synonymy Strategy}

The synonymy strategy translates a SL word using a TL word that has the same or similar meaning (synonymous). This strategy was used 14 times with a percentage of $27 \%$. Two terms were found in a report without a brief; both terms were translated using a ST-oriented approach, which meant that the translator did a ST analysis and translated the terms in accordance with the original author. For example, the term "inguino-scrotal” was translated as الأربي الصفني, while the term "tonic clonic convulsion" was translated as اختلاج رمعي توتري, which are both Arabic medical terms used by specialized medical staff.

However, two terms were translated using the synonymy strategy in which the receivers were medical specialists, and the translator translated the terms in accordance with the receivers (TToriented). For example, the term “dyslipidemia”was translated as عسر شحيمات الدم and the term "right-

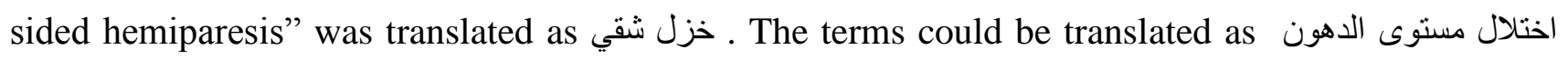
, wلل نصفي للجانب الأيمن من الجسم and w والبروتين في الدم synonyms for the medical terms that were appropriate for the TT receiver rather than using the more common translations.

I found 10 English medical terms associated with a brief that declared that the receivers were laypeople, and were translated using the synonymy strategy. Six of the terms were translated using a synonymous Arabic medical terms, which was not commonly used for laypeople and was hard to understand. For example, the term "hydronephrosis" was translated as موه في الكلية , which literally means water in the kidney; thus, the suggested translation was نوسع في الكلي بسبب احتباس الماء. The term

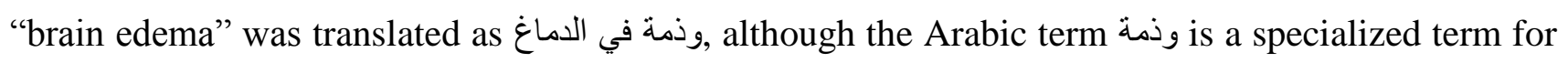
medical uses; in this case, the translator could have used استسقاء, which is more understandable and commonly used by laypeople. The remaining four terms were translated in accordance to their receivers (laypeople); for example, the term "trauma" was translated as اصابة instead of the Arabic medical term رضح, and the term "pressure sore" was translated as قرحات انضغاطية, which can be translated as الناقبة. In other words, the translator translated in accordance with the TT receivers.

\section{Descriptive Equivalence Strategy}

The descriptive equivalence strategy involves translating a ST word by describing the concept of the word in the TL. This strategy was used seven times. In two cases, it was used without a brief for example the term "BPH (benign prostatic hyperplasia)", which was translated as

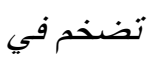


, عدد خلايا وحصو/ت البروستاتا, while the TT did not mention the word حصو/ت, which was a wrong translation. In this case, the suggested translation is تضخم البروستاتا الحميد.

However, another five terms were translated using the descriptive equivalence strategy for a reports that had briefs for non-medical experts receivers. In three terms the brief was considered as in translating the term "hydrocephalus" for example as ضخامة في الرأس. In this case, the translator considered the target receivers and translated the term using more common words than the Arabic medical term استسقاء دماغي. The other two terms, was translated by using the descriptive equivalence strategy without paying attention to the brief as in translating the term "intubated and ventilated" was translated as وضع له انبوب تنفس صناعي, which usually indicates a procedure where the patient is connected to a machine and not only a tube. This strategy did not help the translator convey the exact meaning, which should have been translated as تم تركيب جهاز تتفس صناعي أو تم عمل تهوية صناعية.

\section{Expansion Strategy}

The expansion strategy adds an element of the ST through the translation process for any reason. As previously mentioned for the reduction strategy, since details are important in the translation process, to expand a term that has a specific meaning to another term having part of the original term meaning is a sensitive issue in the translation process. The expansion strategy was used 4 times with a percentage of $8 \%$. For example, one term translated for medical specialists was “cerebral fossa," which was translated as المخ , while the term means (الحفرة الدماغية ( حفرة حقفية. It is very important to use the Arabic medical terms for specialized receivers instead of using an expansion strategy in the translation process.

The remaining three terms that were translated using the expansion strategy had a brief for laypeople receivers. However, using the expansion strategy did not help the translator or the receivers as the translated terms were ambiguous for the laypeople and some of the translations did not make sense. For example, the term "renal cyst" was translated as كيس على القناة البولية, while the correct place of the cyst is on the kidney, in which the suggested translation is كيس كلوي. The term "skull" in the phrase "base of the skull” was translated as عظمة الر أس where the skull means الجمجمة.

Translators of the reports in this study did not use the expansion strategy for the benefit of the receivers. From the analysis, I noticed that the translation was missing information because of the expansion strategy. This was despite being important and where the meaning of the TT would not be correct without including the information.

\section{Naturalization Strategy}

The naturalization strategy is SL form adapted to the TL phonological system. It was used four times in the medical reports that I analyzed; each report had a brief that indicated the receivers were laypeople. For example, the term "clinical examination" was translated as الفحوصات الإكلينيكية even though it could be understood by laypeople, and the translator could have used the easier Arabic 
word, الفحص السريري. The term "HB (hemoglobin)" was translated as الهيموجلوبين, which is more commonly used than the Arabic medical term اليحمور.

However, two terms were translated without considering the TT receivers. For example, the term "chromosomal" was translated as الكروموزوم, while the term "glucose" was translated as الجلوكوز. Since naturalization is an ST-oriented strategy, laypeople will not be able to understand the terms in the TL. For example, the translator could use the Arabic term الصبني as a translation for the term "chromosome." Even though the term is not commonly used, the target receiver can guess the meaning from the TT as a whole.

\section{Transference Strategy}

The transference strategy transfers ST words or expressions into TT without translation. This strategy was used 3 times with a percentage of $6 \%$. All terms had a brief addressing the receivers as laypeople. Table 3 shows examples of terms translated using the transference strategy.

Table 3

Examples of using Transference Strategy

\begin{tabular}{|c|c|c|}
\hline ST & TT & Suggested Translation \\
\hline HTC Packed Red Cell Volume & هيماتوكريت & حجم كريات الدم المكدسة \\
\hline PT Prothrombin Time & بروثرمبين & مقياس العوامل الخارجية لعملية \\
\hline PTT Partial Thromboplastin Time & ثروموبلاتين & مقياس العو امل الداخلية لعملية \\
\hline
\end{tabular}

Transference strategy is a ST-oriented approach. For laypeople, it may be hard to understand text that is translated using the transference strategy. The suggested translation shown in Table 3 gives the receiver a clue of the meaning of the term. However, medical specialists can easily understand a term that was translated using the transference strategy since the ST term remains the same in the TT, but is written in the TL.

\section{Compensation Strategy}

The compensation strategy is a TT-oriented approach that adds further information that was not mentioned in the ST to improve the accuracy of the TT. It was used once in the study sample in a report without a brief. In MR5, the term "presence" was translated as استئصسال, while the ST did not mention the term "hydrocelectomy." 


\section{Literal Translation Strategy}

The literal translation strategy involves a literal word-for-word translation without taking into consideration the TL structure. This strategy was used once in a report that had a brief for laypeople receivers. The term "lung collapse" was translated as تدهور الرئة, while the Arabic medical term is انخماص رئوي. However, the literal translation in this case is more understandable for laypeople than the Arabic medical term.

The total number of problematic terms was 52. TT-oriented strategies were used more than SToriented strategies, which meant that the translators were TT-oriented (covert translation) and used five of the ten (total strategies number) TT strategies. However, three ST-oriented strategies (overt translation) were used out of the ten strategies.

The reduction strategy was most used for a total of 18 times (34\%); the compensation and literal translation strategies were each used once. Figure 1 shows the uses and percentages of each strategy.

Figure 1- The Usage of TS in MR Samples

In the study, I found that the medical translators at KSMC tend to do a covert translation if they do not have a brief and the TT receivers are unknown. Eleven terms were translated without a brief, and eight of those terms were translated using a TT-oriented approach; three terms were translated using a ST-oriented approach. That led us to conclude that the translator uses a TToriented translation to make the TT understandable for all levels of receivers. Forty-one terms found in reports had a brief. Three terms were for specialized target receivers; in these cases, the translators considered the brief and translated according to the receivers using target medical language. However, 38 terms were found to have a brief for laypeople. In most of these cases, the translators did not pay attention to the brief as only 15 terms were translated according to the brief, while 21 terms were translated after ignoring the brief. Two terms were not translated using the reduction strategy, which is a TT-oriented strategy. It was considered as "considered brief".

To summarize, KSMC translators were TT-oriented: 27 terms were translated using the TToriented approach (covert translation) and 25 terms were translated using the ST-oriented approach (overt translation). Table 4 summarizes the findings.

Table 4

Summary of Translators Reaction Toward Each Term in the MR

\begin{tabular}{|c|c|c|c|c|c|c|c|c|c|c|}
\hline \multirow[t]{3}{*}{ Strategy } & \multirow[t]{3}{*}{ Total } & \multicolumn{3}{|c|}{ No Brief } & \multicolumn{6}{|c|}{ Brief } \\
\hline & & \multirow{2}{*}{$\begin{array}{c}\text { ST- } \\
\text { Oriented }\end{array}$} & \multirow{2}{*}{$\begin{array}{c}\text { TT- } \\
\text { Oriented }\end{array}$} & \multirow[t]{2}{*}{ Total } & \multicolumn{2}{|c|}{ Specialized } & \multicolumn{3}{|c|}{ Lay } & \multirow[t]{2}{*}{ Total } \\
\hline & & & & & Considered & Ignored & Considered & Ignored & $\begin{array}{c}\text { Not } \\
\text { translated }\end{array}$ & \\
\hline
\end{tabular}




\begin{tabular}{|c|c|c|c|c|c|c|c|c|c|c|}
\hline Reduction & 18 & 0 & 6 & 6 & 0 & 0 & 5 & 5 & 2 & 12 \\
\hline Synonymy & 14 & 2 & 0 & 2 & 2 & 0 & 4 & 6 & 0 & 12 \\
\hline $\begin{array}{l}\text { Descriptive } \\
\text { Equivalence }\end{array}$ & 7 & 0 & 2 & 2 & 0 & 0 & 3 & 2 & 0 & 5 \\
\hline Expansion & 4 & 0 & 0 & 0 & 0 & 1 & 0 & 3 & 0 & 4 \\
\hline Naturalization & 4 & 0 & 0 & 0 & 0 & 0 & 2 & 2 & 0 & 4 \\
\hline Transference & 3 & 0 & 0 & 0 & 0 & 0 & 0 & 3 & 0 & 3 \\
\hline Compensation & 1 & 1 & 0 & 1 & 0 & 0 & 0 & 0 & 0 & 0 \\
\hline $\begin{array}{c}\text { Literal } \\
\text { Translation }\end{array}$ & 1 & 0 & 0 & 0 & 0 & 0 & 1 & 0 & 0 & 1 \\
\hline Total & 52 & 3 & 8 & & 2 & 1 & 15 & 21 & 2 & \\
\hline
\end{tabular}

TT-oriented translators followed the functionalist approach and prepared the proper translation according to the target receivers' culture. The findings of this study agree with Fraser's (1996) study, which found that the translators considered the explicit briefs and translated accordingly. However,

\section{Translators ST-TT orientations}

ST-oriented

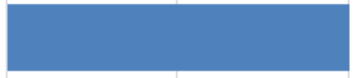

Tा-oriented

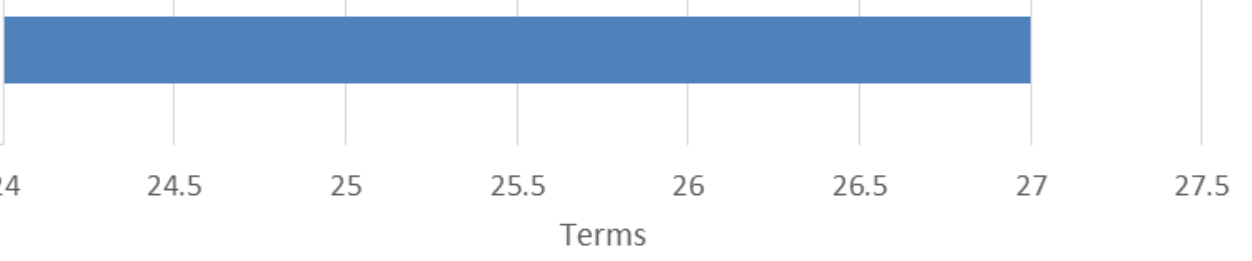

KSMC translators were TT-oriented in 27 terms and ST-oriented in 25 terms as shown in Figure 2.

Figure 2- Translators' Text orientations in MR Samples

These numbers support Nord's (1997) suggestion that professional translators were able to establish a Skopos without having a brief, as KSMC translators were able to connect the ST with the TT in a way that made it understandable for all types of receivers.

\section{Analyzing the Questionnaire Data}


A questionnaire was designed to measure the effect of the brief on the translator's behavior/decision before translating.

Participants were KSMC translators holding bachelor's degrees in English language and translation, having 2 to 4 years' experience at KSMC.

The questionnaire was written in the English language and contained ten semi-open-ended mandatory questions related to the research subject. The questionnaire was pre-tested on two colleagues in the same field of work; their notes were considered before administering the questionnaire.

The questionnaire in this study was designed specifically for KSMC translators who were asked to translate a medical report sample to provide an overview of the importance and impact of the brief on translators. The questionnaire was designed, pre-tested on similar participants, and then approved by the supervisor before being distributed to the participants.

The participants were five translators, all of whom had bachelor's degrees in English language and translation and more than two years' experience in the medical field; in this regard, they were all considered to be professional medical translators.

The results of the questionnaire showed that the most problematic area when translating medical terms is multiple translations for one medical term, which was the main purpose for conducting this study. The receivers of target medical texts vary, which forces translators to do more than simply analyze the ST, as having information about the TT receiver helps to improve the production of the TT so that it is understandable to all receivers. Multiple translations could be a problem if the text is full of medical terms that are not known to non-medical experts; translating these terms using the synonymous "target medical term" will not achieve the main purpose of translation, which is communication, and the target receivers will require further explanation. One participant indicated that the main problems in medical translation are abbreviations and the lack of specialized medical dictionaries. As in any other scientific language, medical language is full of abbreviations, and a major problem in this regard is that one abbreviation could refer to more than one term. Let us examine, for example, the abbreviation "PT":

PT Patient

PT Prothrombin time

PT Physical therapy

It is not only abbreviations that cause confusion, but also the symbols used in writing medical reports, such as "\#” for fracture or "R" for medical prescriptions. In such cases, translators need to consult a medical dictionary specializing in medical abbreviations and then another dictionary for the term that the abbreviation stands for. 
How do translators resolve problematic issues when translating medical terms? Translators need to consult specialized medical dictionaries as well as bilingual dictionaries to translate the medical term from the SL to the TL. However, if the target medical term is not commonly used and difficult for non-medical experts to understand, then the translator has to consult a mono language dictionary, either English-English or Arabic-Arabic in our case, in order to understand the patient's medical condition and consider which translation strategy to use. If the medical report contains medical abbreviations, translators also need to use an abbreviation dictionary to decode the abbreviations.

The other way in which translators solve problematic issues during translation is to use the brief, which provides information about the receivers. This means that translators are aware of the importance of the brief and considered it a key factor in resolving problematic areas.

Although translators consider the brief an important factor, I noticed that during the report analysis, KSMC translators tended to ignore the brief when it specified the receivers as non-medical experts and tended to translate using the synonymy strategy despite the complexity of the target medical term. This may have been due to time limitations or economy of effort.

As for how the translator proceeds if the translation task is not provided by a brief, the majority of questionnaire participants, as previously mentioned, tend to stay close to the TT receivers, which helps them produce an understandable text for all receivers. This confirms the results of the report analysis; however, one participant declared that helshe stays as close to the ST as possible, and another participant stated that helshe refuses to translate without a brief and would contact the original author to request one, as it would not be possible to complete the translation mission without complete information on the TT receivers or function.

In some cases, the original author is available in order to request a brief, and since the request for a brief is the responsibility of the translator, I asked the participants if they would ask for a brief if one was not provided. The questionnaire results in Figure 3 show that $80 \%$ of translators often ask for a brief and feel that the translation task would not be performed effectively without one. One translator, however, declared that helshe rarely asks for one, and that might be because helshe is able to establish the translation based on experience. According to Nord (1997), professional translators are able to establish a translation purpose without a brief based on their previous experience in the field. The purpose of the next question was to determine whether medical translators need the brief before translating. The results indicate that $60 \%$ of the participants said that they need the brief before translating while one participant declared that he/she does not need one. The participants were then asked if they are able to establish a purpose for the translation without a brief; the results showed that all translators said that they are able to establish one, which confirms Nord's claim.

Figure 3- Translators response if They Ask for a Brief (Questionnaire) 


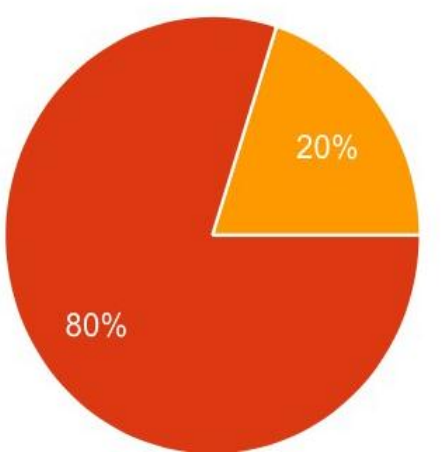

$\begin{array}{rrr}\text { Always } & \mathbf{0} & 0 \% \\ \text { Often } & \mathbf{4} & 80 \% \\ \text { Rarely } & \mathbf{1} & 20 \% \\ \text { Never } & \mathbf{0} & 0 \%\end{array}$

The study participants were asked if they felt they needed a brief for translation. The results show that the majority consider the brief a key factor in the translation process, even though the translators in the report analysis did not follow the brief when it specified the receivers as nonmedical experts, and they still preferred to use the medical target term instead of paraphrasing or using common terms. However, one participant declared that he/she did not need a brief and another one declared that having a brief is irrelevant; this is because either they are able to establish a translation purpose without it, they use the ST as a source of information about the receivers, or they stay close to the ST without paying attention to the TT receivers.

To gauge the translators' thought processes during the establishment of whether they tend to be TT- or ST-oriented, the results show that $60 \%$ of the participants evaluate the ST, based on which they take into consideration both texts, while the other $40 \%$ keep the TT receivers in mind, which means that during the analysis, translators are looking for a brief or more information about the TT receivers.

After collecting the necessary information from the ST, translators were asked if the brief (explicit or implicit) affects their choices of translation strategies. The results show that the brief always or often affects translators' strategies. For confirmation, translators were asked to translate the medical term "hemiparesis," which has multiple translations in the TL. Translators were given information on the target receivers first as medical experts and then again as non-medical experts. The translators considered the brief in both cases. When translating to medical experts, the translators chose all applicable translations/strategies, knowing that medical experts would understand the term and would have the necessary medical case knowledge. However, when translating the same medical term for non-medical receivers, the translators tended to use the paraphrase strategy, knowing that non-medical experts needed explanation regarding the target Arabic medical term “خزل شقي." This indicated to us the importance of the brief and how it affects the translator's choice of translation strategy. 


\section{Conclusion}

The register of medical language defines its complexity. When specialized medical staff write medical reports according to their medical language, translators must translate this medical language according to its receivers. In this study, I found that medical translators tend to be TT-oriented regardless of whether they have a brief or not in the report analysis, the same results found in the questionnaire as none of the translators declared to be ST- oriented, they either TT-oriented or they put in consideration the both texts, which means that they try to use simple language that will help any receiver understand the translation.

\section{Recommendations}

Based on the finding of the study, I recommend the following:

1- Medical translators should have an explicit brief that indicates the type of receiver; translators should request a brief if it is not supplied. A brief will help the translators to reach their goal of producing a TT that is understandable and professional.

2- It is recommended that a translator takes a course in medical translation because using everyday English language is not sufficient for this field. Any mistake in translation could potentially lead to a serious problem for the patients or the third party, such as the court or insurance companies, who request the translation.

\section{REFERENCES}

Fraser, Janet. "Mapping the Process of Translation." Meta Meta: Journal Des Traducteurs 41.1 (1996), pp. 84. Web

Nord, C.. Translating as a Purposeful Activity: Functionalist Approaches Explained. London: Routledge.(1997).

Schjoldager, Anne. Hermes, Journal of Linguistics 30th ser. (n.d.): n. pag. 2003. Web.

Jääskeläinen,, Riitta. "Thematic Network on Empirical and Experimental Research in Translation." Professional vs. Non-professional Translating: A Think-aloud Protocol Study|

Thematic Network on Empirical and Experimental Research in Translation. N.p., n.d. Web. 21 Dec. 2016

Reiss, K. Translation Criticism the Potentials and Limitation, Categories and Criteria for Translation Quality Assessment. New York: Routledge (2014).

Halliday, M. A. K. An Introduction to Functional Grammar. London: E. Arnold, 1985. Print. House, Juliane. Translation Quality Assessment: A Model Revisited. Tübingen: G. Narr, 1997. Web 